\title{
Angiotensin-II Receptor Blocker Exerts Cardioprotection in Diabetic Rats Exposed to Hypoxia
}

\author{
Sakiko Inamoto, MD; Tetsuya Hayashi, MD; Naoko Tazawa, MS*; Tatsuhiko Mori, MD; \\ Chika Yamashita, BS*; Daisuke Nakano, PhD*; Yasuo Matsumura, $\mathrm{PhD} *$; \\ Nobuaki Okuda, MD; Koichi Sohmiya, MD; Akiko Sakai, PhD**; \\ Eisuke Furuya, $\mathrm{PhD}^{* *}$; Yasushi Kitaura, MD
}

\begin{abstract}
Background Hypoxia caused by sleep apnea might be associated with an increased risk of cardiovascular events in subjects with metabolic syndrome. The aim of this study was to examine the effect of hypoxia on the left ventricular (LV) myocardium and evaluate the cardioprotective effect of an angiotensin-II receptor blocker $(\mathrm{ARB})$ in diabetic rats.

Methods and Results Male Otsuka Long-Evans Tokushima Fatty (OLETF) rats at 30 weeks of age $(n=30)$ were divided into 2 groups that were treated with vehicle or candesartan $0.2 \mathrm{mg} \cdot \mathrm{kg}^{-1}$. day ${ }^{-1}$. The animals were housed in a hypoxic gas chamber (oxygen, $10.0 \pm 0.5 \%$, mean \pm standard deviation) for 2 weeks. Hypoxia increased right ventricular (RV) systolic pressure (hypoxia; $78 \pm 14 \mathrm{mmHg}$ vs control; $22 \pm 5, \mathrm{p}<0.05$ ), but did not increase LV systolic pressure $(131 \pm 23 \mathrm{mmHg}$ vs $121 \pm 10)$. Hypoxia exacerbated the degeneration of cardiomyocytes, and accelerated the expression of hypoxia inducible factor-la (HIF-la) and vascular endothelial growth factor (VEGF) in the myocardium. Treatment with ARB decreased RV and LV pressures $(46 \pm 7$ and $100 \pm 18 \mathrm{mmHg}$, respectively), suppressed the expression of HIF-la and VEGF, and preserved the fine structure of the LV myocardium.

Conclusions ARB exhibited cardioprotection under hypoxia, in part through the reduction of blood pressure and cytokine expression, in OLETF rats. Thus, ARB might be a potent agent for the treatment of diabetic patients with the complication of sleep apnea. (Circ J 2006; 70: 787-792)
\end{abstract}

Key Words: Angiotensin-II receptor blocker; Diabetes mellitus; Hypoxia; Hypoxia inducible factor-la; Ventricular remodeling

$\mathbf{T}$ he metabolic syndrome is a clustering of atherosclerotic cardiovascular disease risk factors, 1 and sleep apnea syndrome (SAS) is common among patients with metabolic syndrome. The resultant hypoxic condition may be associated with increased cardiovascular morbidity and mortality? It was recently reported that SAS increases the risk of fatal and non-fatal cardiovascular events in association with ventricular dysfunction? Interestingly, some sleep disturbance in patients with diabetes mellitus (DM) might result from the deleterious effects of the disease on central control of respiration.

Hypoxia causes a wide range of responses in organisms at both the systemic and cellular levels 5 The transcriptional response to lower oxygen levels is mediated by hypoxia inducible factor-la (HIF-la), a master regulator of genes expressed in response to hypoxia, including the genes for vascular endothelial growth factor (VEGF), endothelin (ET)-1, and inducible nitric oxide synthase?,8 Thus, the hypoxic condition will be much more deleterious to the diabetic heart, because diabetes itself is known to increase the risk of cardiovascular events.

(Received December 13, 2005; revised manuscript received March 7, 2006; accepted March 14, 2006)

Third Department of Medicine, Osaka Medical College, *Osaka University of Pharmaceutical Sciences and **Department of Chemistry, Osaka Medical College, Takatsuki, Japan

Mailing address: Tetsuya Hayashi, MD, Third Department of Medicine, Osaka Medical College, 2-7 Daigakumachi, Takatsuki 569-8686,

Japan. E-mail: in3015@poh.osaka-med.ac.jp
Angiotensin-II increases the level of HIF-la translation by a reactive oxygen species (ROS)-dependent activation of the phosphatidylinositol 3-kinase pathway, which acts on the 5'-untranslated region of HIF- 1 a 9,10 Moreover, high plasma angiotensin-II levels and increased expression of angiotensin-II type 1 receptor (AT1 receptor) have been reported in patients with SAS!1

Thus, the purpose of this study was to examine the effect of hypoxia on the diabetic heart and to evaluate the efficacy of cardioprotection by treatment with angiotensin-II receptor blocker (ARB).

\section{Methods}

\section{Experimental Protocol}

Male Otsuka Long-Evans Tokushima Fatty (OLETF) rats $(n=30)$ at 30 weeks of age, exhibiting type $2 \mathrm{DM}$, were divided into 2 groups and housed in a normobaric hypoxic chamber $\left(\mathrm{O}_{2}: 10.0 \pm 0.5 \%\right)(\mathrm{n}=18)$ or under normoxic conditions $(n=12)$ for 2 weeks. Rats in the hypoxic gas chamber were subdivided into 2 groups that were treated with vehicle $(\mathrm{n}=10)$ or the ARB candesartan $0.2 \mathrm{mg} \cdot \mathrm{kg}^{-1} \cdot$ day $^{-1}$ $(\mathrm{n}=8)$, which was administered intraperitoneally using an osmotic mini-pump (ALZET ${ }^{\circledR}$, CA, USA)!2 The chamber was opened 3 times each week to provide the animals with fresh food (normal cholesterol diet) and water, and clean bedding.

After the 2-week experimental period, catheterization was done under intraperitoneal anesthesia with ketamine 
Table 1 Effect of Hypoxia on Diabetic Rat

\begin{tabular}{lccc}
\hline \hline & \multirow{2}{*}{$\begin{array}{c}\text { Normoxia } \\
(n=12)\end{array}$} & \multicolumn{2}{c}{ Hypoxia } \\
\cline { 3 - 4 } & & Vehicle $(n=10)$ & ARB $(n=8)$ \\
\hline Body weight $(g)$ & $612 \pm 44$ & $447 \pm 41^{*}$ & $426 \pm 42^{*}$ \\
Heart weight $(g)$ & $1.4 \pm 0.1$ & $1.3 \pm 0.1$ & $1.2 \pm 0.1^{*}$ \\
Hw/Bw $(\mathrm{mg} / \mathrm{g})$ & $2.3 \pm 0.2$ & $2.9 \pm 0.3^{*}$ & $2.6 \pm 0.3$ \\
Glucose $(\mathrm{mg} / \mathrm{dl})$ & $239 \pm 35$ & $200 \pm 21$ & $206 \pm 25$ \\
TC $(\mathrm{mg} / \mathrm{dl})$ & $124 \pm 12$ & $73 \pm 8^{*}$ & $74 \pm 11^{*}$ \\
LDL-C $(\mathrm{mg} / \mathrm{dl})$ & $10 \pm 2$ & $11 \pm 2$ & $11 \pm 2$ \\
TG $(\mathrm{mg} / \mathrm{dl})$ & $147 \pm 28$ & $69 \pm 18^{*}$ & $68 \pm 21^{*}$
\end{tabular}

$A R B$, angiotensin-II receptor blocker; $H w / B w$, heart/body weight ratio; $T C$ total cholesterol; $L D L-C$, low-density lipoprotein cholesterol; TG, triglycerides.

$* p<0.05$ vs Normoxia.

$80 \mathrm{mg} / \mathrm{kg}$ and xylazine $12 \mathrm{mg} / \mathrm{kg}$. A 2 Fr Micro-tip ${ }^{\circledR}$ catheter (model PR-249, Millar Instruments, Houston, TX, USA) was introduced through the right jugular vein or the right carotid artery to measure right or left ventricular (LV) pressures, respectively. Blood samples were collected for measurement of plasma glucose, total cholesterol (TC), lowdensity lipoprotein cholesterol (LDL-C) and triglycerides (TG). All procedures were performed in accordance with the institutional guidelines for animal research.

\section{Light and Electron Microscopy}

After the hemodynamic measurements, the heart was excised, and part of the right ventricular (RV) and LV myocardium was fixed in $10 \%$ formaldehyde, embedded in paraffin and cut into $4 \mu \mathrm{m}$-thick sections for light microscopy. The shortest diameters of cardiomyocytes were measured only in nucleated transverse sections stained with hematoxylin-eosin under a light microscope at a magnification of $\times 400$. In the sections stained with Sirius red, interstitial fibrosis was measured using a computer-assisted image analysis and the percentage of fibrosis was calculated $!^{3}$

To examine the effect of hypoxia on the fine structure of the LV myocardium, which is not affected by pulmonary hypertension, ${ }^{14}$ part of the LV free wall was fixed in $4 \%$ paraformaldehyde containing $0.25 \%$ glutaraldehyde and $4.5 \%$ sucrose. Ultrathin sections created from the embedded blocks were stained with uranyl acetate and lead citrate, and were examined with a Hitachi H-7650 electron microscope. ${ }^{15}$

\section{Immunohistochemistry for HIF-la and VEGF}

Additional sections cut from each paraffin block were pretreated with $3 \% \mathrm{H}_{2} \mathrm{O}_{2}$ after dewaxing and rehydration. After incubation with normal blocking serum, the sections were incubated overnight at $4^{\circ} \mathrm{C}$ with monoclonal antibody against HIF-la (Novus Biological, CO, USA) or VEGF (sc-7269, Santa Cruz Biotechnology, CA, USA). After washing and incubation with secondary antibody, the sections were treated with the peroxidase substrate solution (Vectastain 3'3'-diaminobenzidine substrate kit, Vector Laboratories, CA, USA)! 6

After immunostaining, digital images of each section were obtained with a digital camera (Fujix Digital Camera HC-300Z) mounted on a Nikon Microphot-FXA. Color images were obtained from 5 randomly selected separate high-power fields $(\times 200)$ in 5 sections per rat $(n=4)$. Each image covered an area of 780,402 pixels and was analyzed
Table 2 Hemodynamic Data, Diameter of Cardiomyocytes, and Percetage of Fibrosis (\% Fibrosis) in Diabetic Rats

\begin{tabular}{lccc}
\hline \hline & \multirow{2}{*}{$\begin{array}{c}\text { Normoxia } \\
(n=10)\end{array}$} & \multicolumn{2}{c}{ Hypoxia } \\
\cline { 3 - 4 } & & Vehicle $(n=9)$ & $A R B(n=6)$ \\
\hline Heart rate (beats/min) & $293 \pm 21$ & $329 \pm 36$ & $325 \pm 36$ \\
RVsys $(\mathrm{mmHg})$ & $22 \pm 5$ & $78 \pm 14^{*}$ & $46 \pm 7^{*} \#$ \\
LVsys $(\mathrm{mmHg})$ & $121 \pm 10$ & $131 \pm 23$ & $100 \pm 18^{\#}$ \\
Diameter $(\mu \mathrm{m})$ & & & \\
RV & $17.1 \pm 1.1$ & $20.2 \pm 1.4^{*}$ & $18.1 \pm 0.8^{\#}$ \\
LV & $21.1 \pm 2.1$ & $24.8 \pm 1.2^{*}$ & $20.9 \pm 1.7^{\#}$ \\
$\%$ Fibrosis & $12.2 \pm 3.2$ & $15.8 \pm 1.8$ & $10.7 \pm 3.2^{\#}$ \\
\hline
\end{tabular}

$A R B$, angiotensin-II receptor blocker; RVsys and LVsys, right and left ventricular systolic pressure, respectively; Diameter, mean diameter of cardiomyocytes.

${ }^{*} p<0.05$ vs Normoxia, ${ }^{\#} p<0.05$ vs Vehicle.

using NIH Image 1.60 software. Both intensity and area were analyzed by the method published previously 17 The data from all the examined sections were used to calculate the $\%$ area of positive pixels relative to the total examined area in pixels.

\section{Western Blotting for HIF-la}

Frozen LV samples were homogenized with 5 volumes of $20 \mathrm{mmol} / \mathrm{L} \mathrm{HEPES}-\mathrm{NaOH}$ (pH7.8), $10 \mathrm{mmol} / \mathrm{L} \mathrm{KCl}$, $1.5 \mathrm{mmol} / \mathrm{L} \mathrm{MgCl} 2,0.1 \mathrm{mmol} / \mathrm{L}$ EDTA, $1 \mathrm{mmol} / \mathrm{L} \mathrm{Na-ortho-}$ vanadate, and protease inhibitor cocktail (Sigma, Saint Louis, MO, USA), and sonicated ${ }^{18}$ The insoluble material was removed by centrifugation at $15,000 \mathrm{G}$ for $20 \mathrm{~min}$. The protein concentration of the supernatants was estimated using the Bio-Rad protein assay (Bio-Rad, CA, USA), and equal amounts of protein ( $45 \mu \mathrm{g}$ of protein/lane) were separated by $8 \%$ SDS-PAGE and transferred to polyvinylidene difluoride membranes (Millipore, Bedford, MA, USA). The membranes were incubated with the primary antibody (Novus Biological, CO, USA), and the proteins were visualized by using ECL plus Western Blotting Detection Reagents (Amersham Pharmacia, Piscataway, NJ, USA). The intensity of the protein bands was quantified by scanning densitometry.

\section{Tissue ET-1 Assay}

ET-1 was extracted from the RV as described elsewhere ${ }^{19}$ Briefly, the tissues were weighed and homogenized for $60 \mathrm{~s}$ in $4 \mathrm{ml}$ of ice-cold organic solution (chloroform/methanol, 2:1, including $1 \mathrm{mmol} / \mathrm{L} \mathrm{N}$-ethylmaleimide). The homogenates were left overnight at $4^{\circ} \mathrm{C}$ and then mixed with $0.4 \mathrm{ml}$ of $0.09 \%$ trifluoroacetic acid (TFA). The homogenates were then centrifuged at $3,000 \mathrm{G}$ for $30 \mathrm{~min}$ and the supernatant was stored. Aliquots of the supernatant were diluted 1:10 with a $0.09 \%$ TFA solution and applied to Sep-Pak C18 cartridges. Each sample was eluted with $3 \mathrm{ml}$ of $63.3 \%$ acetonitrile and $0.1 \%$ TFA, dried in a centrifugal concentrator, and the dried residue was then reconstituted in assay buffer for radioimmunoassay (RIA) of the clear solution. The recovery of ET-1 was approximately $80 \%$. RIA for tissue ET-1 was performed as described elsewhere, using ET-1 antiserum, ${ }^{20}$ which does not cross-react with big ET-1 and can distinguish between ET (1-21) and the C-terminally extended form, ET (1-39)?21, 22

\section{Statistical Analysis}

Data are expressed as mean \pm standard deviation, and statistical analysis was performed by 1-way ANOVA. Post 

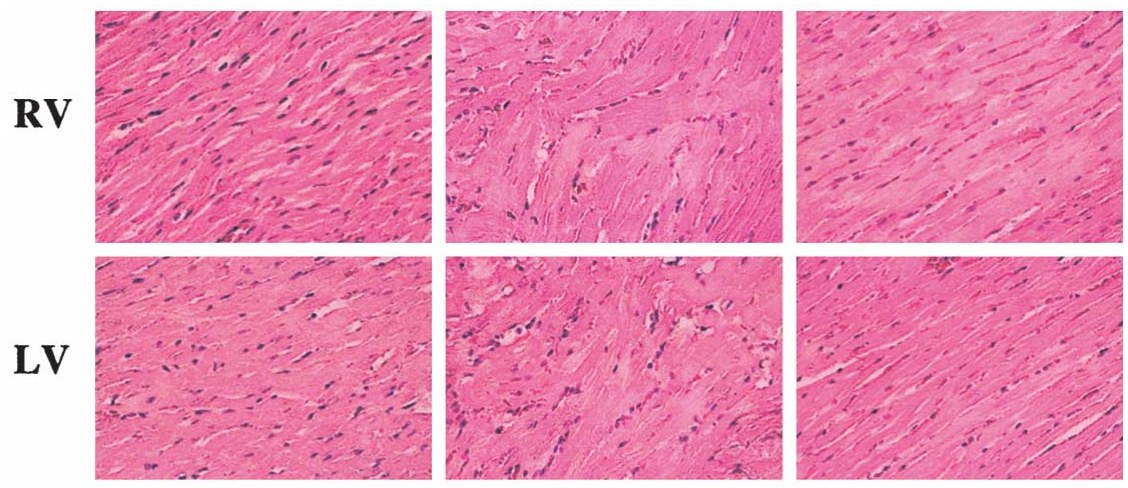

Normoxia

Vehicle

ARB

Hypoxia
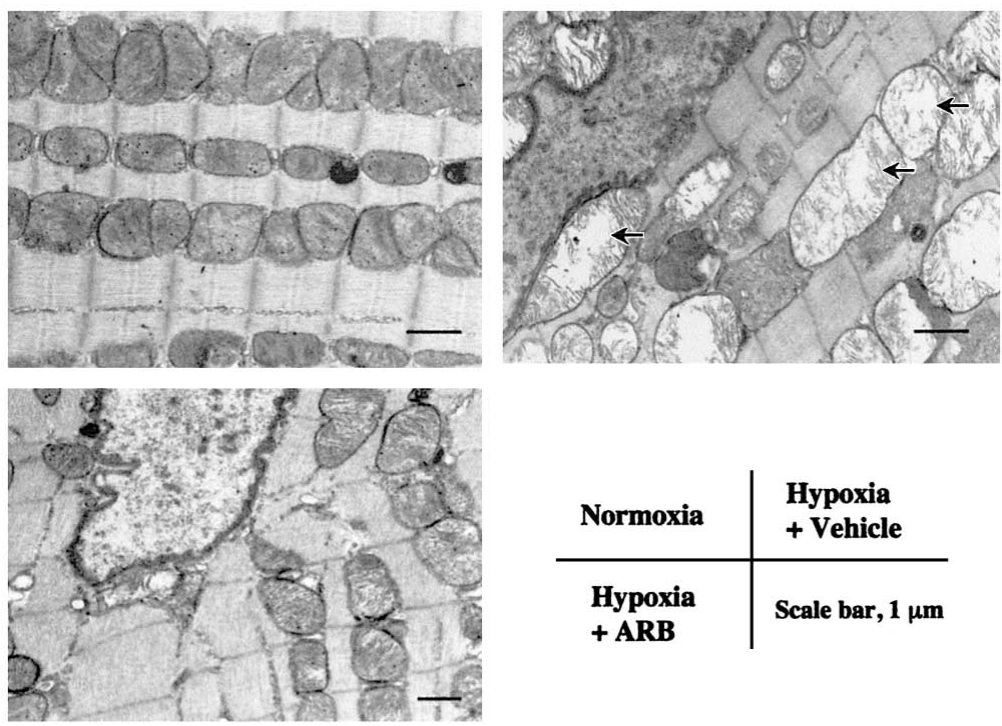

Fig 1. Representative light micrographs of right and left ventricular (RV and LV) myocardium (hematoxylin-eosin; $\times 100$ ). In the rats kept under normoxia, mild hypertrophy and disarray of myofibers can be seen in both the RV and LV myocardium. Hypoxia exacerbated the hypertrophy and disarray of myofibers in the LV as well as the RV myocardium, which angiotensin-II receptor blocker (ARB) suppressed, and the light microscopic findings are similar to those of the rats kept under normoxia. hoc analysis of multiple comparisons was corrected with Dunnett's test. Differences between pairs were determined by Student's t-test, and significance was recognized at $\mathrm{p}<0.05$.

\section{Results}

Heart and Body Weight, Plasma Glucose, and Lipids

Hypoxia significantly decreased the body weight and consequently increased the ratio of heart weight to body weight ( $\mathrm{Hw} / \mathrm{Bw}$ ratio). Treatment with $\mathrm{ARB}$ significantly decreased the Hw and suppressed the increase of the $\mathrm{Hw} / \mathrm{Bw}$ ratio (Table 1 ).

There was no significant difference in the plasma glucose or LDL-C level among the 3 groups. However, the TC and TG levels were significantly decreased in the rats exposed to hypoxia, and ARB exhibited no effect on these decreases (Table 1).

\section{Hemodynamic Data}

The heart rate tended to increase in the rats exposed to hypoxia, but there was no difference between groups treated with vehicle and ARB (Table 2). Hypoxia elevated the RV systolic pressure up to $78 \mathrm{mmHg}$, but 2 weeks of hypoxic stress did not affect the LV systolic pressure. The treatment with ARB significantly decreased both the RV and LV pressures (Table 2).

\section{Histological Findings}

In the rats kept in normoxic conditions, mild hypertrophy and disarray of myofibers were observed in both the RV and LV myocardium. Hypoxia significantly increased the mean diameter of cardiomyocytes and exacerbated the degeneration in both the LV and RV myocardium (Fig 1, Table 2). In the rats kept in hypoxic conditions, treatment with ARB significantly suppressed the hypertrophy of cardiomyocytes, decreased interstitial fibrosis, and led to light microscopic findings similar to those of the rats kept in normoxic conditions.

Under electron microscopy, ballooning and loss of cristae were seen in many mitochondria of myocytes from the LV myocardium in the rats exposed to hypoxia, whereas mild deformity of mitochondria were observed in tissue of the rats kept under normoxic conditions (Fig 2). Treatment with ARB tended to decrease the number of degenerated mitochondria and to improve the preservation of the fine structure of the LV myocardium.

Immunohistochemistry and Western Blot Analysis

Hypoxia significantly increased HIF-la and VEGF ex- 


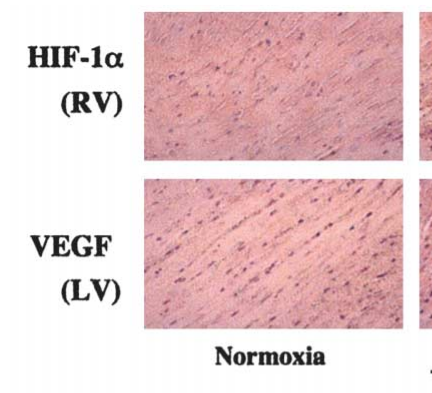

HIF-1 $\alpha$

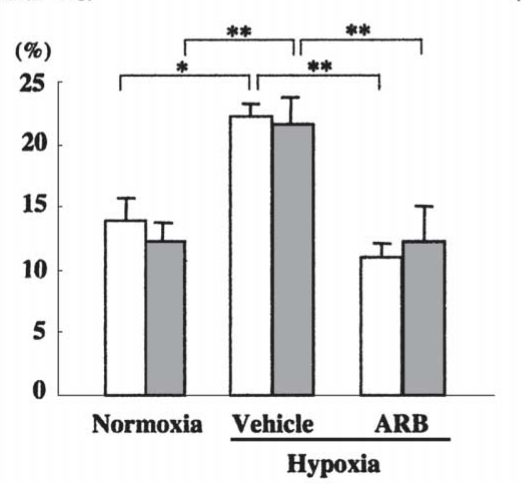

$\mathbf{A}$

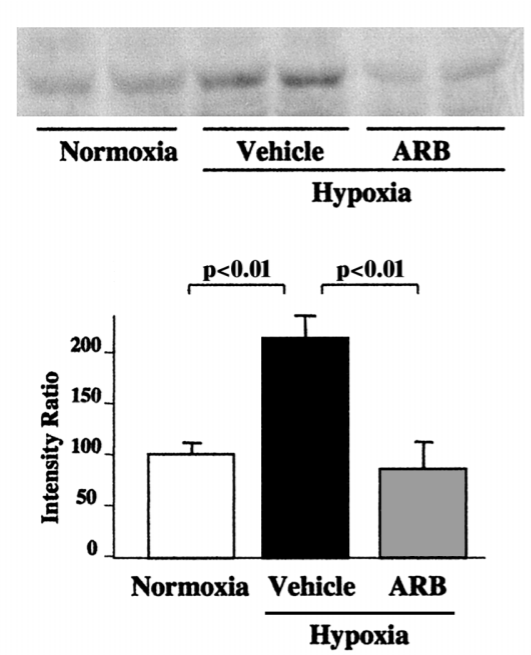

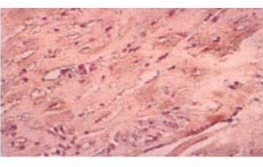
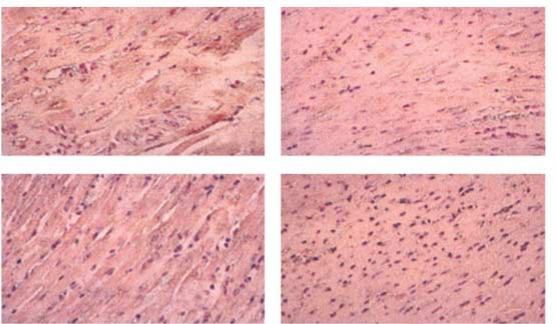

Vehicle
ARB

Hypoxia

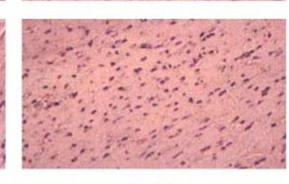

Fig 3. Immunohistochemistry and \% area of hypoxia inducible factor-la (HIF-la ) and vascular endothelial growth factor (VEGF) expression. Representative micrographs for HIF-la are from the right ventricular (RV) myocardium and those for VEGF are from the left ventricular (LV) myocardium. The mean \%area of HIF-la and VEGF staining significantly increased in the rats exposed to hypoxia. Treatment with angiotensin-II receptor blocker (ARB) significantly attenuated the increase of HIF-la and VEGF expression in both the RV and LV myocardium. There was no significant difference in the \%area of staining between the RV and LV myocardium.
B

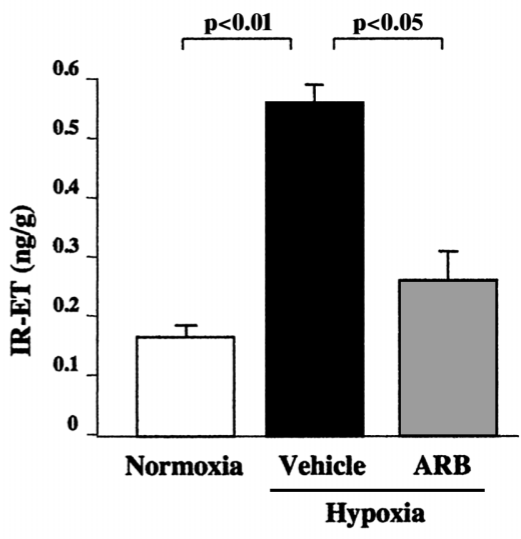

Fig 4. Expression of hypoxia inducible factor-la (HIF-la) and endothelin (ET)-1. (A) HIF- la expression in the left ventricular myocardium was increased by hypoxia, and this increase was significantly suppressed by angiotensin-II receptor blocker (ARB) treatment. These findings are in accord with those of quantitative immunohistochemistry (Fig 3). Results are expressed as the mean \pm standard deviation of the band intensity ratio, and values were normalized to the control $(n=5)$. (B) Hypoxia significantly increased the immunoreactive ET-1 content (IR-ET) in the right ventricular myocardium, and this increase was significantly suppressed by treatment with ARB. pression in both the RV and LV myocardium (Figs 3,4). Although HIF-la tended to increase more in the RV and VEGF to increase more in the LV than the respective counterparts, there was no significant difference between the RV and LV. Treatment with ARB significantly attenuated the increase of HIF-la and VEGF in both the RV and LV myocardium (Figs 3,4).

\section{ET-1 Assay}

Hypoxia significantly increased the ET-1 content in the RV myocardium, and ARB treatment effectively suppressed the increase (Fig 4).

\section{Discussion}

Intermittent hypoxia, which is often induced by sleep apnea, has been reported to increase cardiovascular events in patients with both the metabolic syndrome and DM? ${ }^{2-4}$ The renin-angiotensin system may be involved in the molecular responses to the hypoxic stress, but the precise mechanisms are not clear. Therefore, we examined the hypothesis that hypoxia might induce exacerbation of myocardial degeneration in the diabetic heart and ARB might exert cardioprotection through modulation of cytokine expression.

We previously reported that chronic hypoxia elevated the RV pressure in apolipoprotein E-knockout mice ${ }^{14}$ In the present study, using OLETF rats to represent type 2 $\mathrm{DM}$, elevated RV but not LV pressure was observed as well. On the other hand, the body weight of rats exposed to hypoxia was significantly lower than that of rats kept under normoxia, and consequently the ratio of heart to body weight was increased. Although TC and TG levels decreased significantly, hypoxia had little effect on the plasma 
glucose and LDL-C levels. The OLETF rats exposed to hypoxia clearly looked exhausted and the amount of food intake per day was reduced to three-quarters that of rats kept under normoxia. Increased oxidative stress has been found at the age of 32 weeks in OLETF rats kept under normoxia.23 Thus it is possible that diabetic rats are more susceptible to hypoxia than normal rats. Our preliminary study indicating that the survival ratio of diabetic rats exposed to severe hypoxia $\left(\mathrm{O}_{2}: 7-8 \%\right)$ was lower than that of normal rats (data not shown) support this hypothesis.

Treatment with ARB significantly reduced the RV and LV systolic pressures, although all the other parameters, including the ratio of heart weight to body weight, plasma levels of glucose and lipids, and heart rate, showed no change in response to the treatment. The dose of ARB used in this study was based on a previous study ${ }^{12}$ and might be suitable for protection against oxidative stress, However, the $\mathrm{AT}_{1}$ receptor might be upregulated in the cardiovascular system when exposed to high glucose levels plus hypoxic conditions, and ARB could exhibit a strong blood pressurelowering effect 11,24 Further studies to examine the effect of non-hypotensive doses of ARB may be required.

Histologically, mild hypertrophy and disarray of myofibers were exacerbated by hypoxia in both the RV and LV myocardium, although after 2 weeks of hypoxia there was a small effect on the interstitial fibrosis (Fig 1, Table 2). The degeneration of cardiomyocytes in the RV myocardium might have been caused by the elevated pressure. ET-1 is increased in the RV myocardium and is thought to be increased in the LV myocardium as well1,4 and this might also worsen the degeneration of cardiomyocytes (Fig 4). On the other hand, the histological changes in the LV myocardium, including hypertrophy of cardiomyocytes, mitochondrial ballooning and loss of cristae, appeared not to be markedly affected by the elevated RV pressure during the observation period of this study (Fig 2). Therefore, hypoxia might accelerate the myocardial degeneration in the diabetic heart, even after a short period.

Recently, Ryan et al reported that in a cell culture model intermittent hypoxia activated inflammatory pathways but did not lead to HIF-la stabilization. 25 They showed that sustained hypoxia $\left(1 \% \mathrm{O}_{2}, 5 \% \mathrm{CO}_{2}\right.$ for $\left.24 \mathrm{~h}\right)$ activated HIFla, but intermittent hypoxia did not. Although their model differs from the pattern of intermittent hypoxemia that occurs in SAS patients, inflammatory cytokines might be involved in the pathogenesis of cardiovascular disease in SAS. In the present study, hypoxia enhanced the HIF-la expression in both the RV and LV myocardium of the diabetic rat heart (Figs 3,4). HIF-la has been reported to control the expression of many pro-angiogenic genes, and we also observed increased VEGF and ET-1 expression in the myocardium 26 Although no significant difference was observed in the percentage area of immunostaining between the RV and LV myocardium, VEGF tended to increase more markedly in the LV than in the RV myocardium (Fig 3). Further studies are needed to determine whether VEGF expression correlates with the extent of degeneration of the myocardium.

Several studies have shown that exposure to hypoxic stress induces ROS production in the mitochondria of vascular cells, which might contribute to the development of various pathophysiological states? ${ }^{27,28}$ We have also reported hypoxia-increased levels of both ROS and activated NADPH oxidase in the aortas of apoE-KO mice! ${ }^{14}$ Although we could not examine the oxidative stress in myocardial cells or perform a quantitative evaluation of the fine structure in the present study, the mitochondrial degeneration was more prominent than other changes of nuclei, myofibrils, and cytoplasmic organelles in the diabetic heart (Fig 2). These findings suggest that there is increased mitochondrial susceptibility to hypoxia in the diabetic heart.

Treatment with ARB reduced the hypoxia-induced histological changes in the diabetic heart, suggesting the important role of the renin-angiotensin system in the remodeling of the diabetic heart by hypoxia29,30 Although the precise mechanisms of the cardioprotection induced by ARB may be complex, the drug significantly suppressed HIF-la, VEGF, and ET-1 expression and preserved the mitochondrial structure. We could not examine the fetal gene expressions in the hypertrophied myocardium in the diabetic heart, and to evaluate the effect of hypoxia on cardiomyocytes more precisely, A-type and B-type natriuretic peptides should be examined 31 Comparing the cardioprotection of ARB and other vasodilators under hypoxic conditions needs to be done to clarify the role of the reninangiotensin system.

We have reported that ARB preserved LV diastolic function in diabetic rat hearts and decreased inflammatory

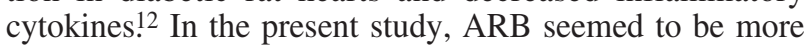
efficient in lowering blood pressure and inducing cardioprotection than in our previous study conducted under normoxic conditions, although the dose of candesartan was the same. One major reason would be the reduction in body weight of the rats exposed to hypoxia. Because we used an osmotic pump, we could not change the dose after the intraperitoneal implantation. Another reason might be upregulation of the $\mathrm{AT}_{1}$ receptor because of the high glucose level in hypoxic conditions. ${ }^{11}$ Further examination with a small and constant dose of ARB needs to be done.

In conclusion, ARB exerted cardioprotection under hypoxia, in part through suppression of blood pressure and cytokine expression, in OLETF rats. Thus, ARB might be a potent agent for the treatment of diabetic patients with the complication of sleep apnea.

\section{Acknowledgments}

We would like to express our gratitude to Y. Kitaguni, S. Uchida, C. Ohta, Y. Ogami, and Y. Nakahira for their expert technical assistance, and acknowledge the assistance of $F$. Maeda during the preparation of this manuscript.

\section{References}

1. Ford ES, Giles WH, Dietz WH. Prevalence of the metabolic syndrome among US adults: Findings from the third national health and nutrition examination survey. JAMA 2002; 287: 356-359.

2. Coughlin SR, Mawdsley L, Mugarza JA, Calverley PM, Wilding JP. Obstructive sleep apnoea is independently associated with an increased prevalence of metabolic syndrome. Eur Heart J 2004; 25: $735-741$.

3. Martin JM, Carrizo SJ, Vicente E, Agusti AGN. Long-term cardiovascular outcomes in men with obstructive sleep apnoea-hypopnoea with or without treatment with continuous positive airway pressure: An observational study. Lancet 2005; 365: 1046-1053.

4. Resnick HE, Redline S, Shahar E, Gilpin A, Newman A, Walter R, et al. Sleep Heart Health Study: Diabetes and sleep disturbances: Findings from the Sleep Heart Health Study. Diabetes Care 2003; 26: 702-709.

5. Bunn HF, Poyton RO. Oxygen sensing and molecular adaptation to hypoxia. Physiol Rev 1996; 76: 839-885.

6. Semenza GL, Roth PH, Fang HM, Wang GL. Transcriptional regulation of genes encoding glycolytic enzymes by hypoxia-inducible factor 1. J Biol Chem 1994; 269: 23757-23763.

7. Semenza GL. HIF-la mediator of physiological and pathophysiological responses to hypoxia. J Appl Physiol 2000; 88: 1474-1480. 
8. Piacentini L, Karliner JS. Altered gene expression during hypoxia and reoxygenation of the heart. Pharmacol Ther 1999; 83: 21 - 37 .

9. Richard DE, Berra E, Pouysségur J. Nonhypoxic pathway mediates the induction of hypoxia-inducible factor la in vascular smooth muscle cells. J Biol Chem 2000; 275: 26765 -26771.

10. Pagé EL, Robitaille GA, Pouysségur J, Richard DE. Induction of hypoxia-inducible factor-la by transcriptional and translational mechanisms. J Biol Chem 2002; 277: 48403-48409.

11. Sodhi CP, Kanwar YS, Sahai A. Hypoxia and high glucose upregulate $\mathrm{AT}_{1}$ receptor expression and potentiate ANG II-induced proliferation in VSM cells. Am J Physiol Heart Circ Physiol 2003; 284: 846-852.

12. Hayashi T, Sohmiya K, Ukimura A, Endoh S, Mori T, Shimomura $\mathrm{H}$, et al. Angiotensin II receptor blockade prevents microangiopathy and preserves diastolic function in the diabetic rat heart. Heart 2003; 89: $1236-1242$

13. Mori T, Hayashi T, Sohmiya K, Okuda N, Shimomura H, Ohkita M, et al. Mechanisms of combined treatment with celiprolol and candesartan for ventricular remodeling in experimental heart failure. Circ J 2005; 69: 596-602.

14. Nakano D, Hayashi T, Tazawa N, Yamashita C, Inamoto S, Okuda $\mathrm{N}$, et al. Chronic hypoxia accelerates the progression of atherosclerosis in apolipoprotein E-knockout mice. Hypertens Res 2005; 28: $837-845$.

15. Hayashi T, James TN, Buckingham DC. Ultrastructure and immunohistochemistry of the coronary chemoreceptor in human and canine hearts. Am Heart J 1995; 129: 946-959.

16. Hayashi T, Ijiri Y, Kawamura K, Shimomura H, Okabe M, Terasaki $\mathrm{F}$, et al. Increased digitalis-like immunoreactive substances in patients with hypertrophic cardiomyopathy. Eur Heart J 2000; 21: $296-305$.

17. Okuda N, Hayashi T, Mori T, Inamoto S, Okabe M, Mieno S, et al Nifedipine enhances the cardioprotective effect of an angiotensin-II receptor blocker in experimental heart failure. Hypertens Res 2005; 28: $431-443$.

18. Chun YS, Hyun JY, Kwak YG, Kim IS, Kim CH, Choi E, et al. Hypoxic activation of the atrial natriuretic peptide gene promoter through direct and indirect actions of hypoxia-inducible factor-1. Biochem J 2003; 370: 149-157.

19. Nishida M, Hayashi T, Ieshima M, Eshiro K, Akiyoshi K, Takaoka $\mathrm{M}$, et al. Selective endothelin ETb receptor antagonist improves left ventricular function but exaggerates degeneration of cardiomyocytes in J2N-k hamsters. Circ J 2005; 69: 107-113.

20. Matsumura Y, Ikegawa R, Takaoka M, Morimoto S. Conversion of porcine big endothelin to endothelin by extract from the porcine aortic endothelial cells. Biochem Biophys Res Commun 1990; 167: $203-$ 210.

21. Hexum TD, Hoeger C, Rivier JE, Baird A, Brown MR. Characterization of endothelin secretion by vascular endothelial cells. Biochem Biophys Res Commun 1990; 167: 294-300.

22. Matsumura Y, Kuro T, Kobayashi Y, Konishi F, Takaoka M, Wessale $\mathrm{JL}$, et al. Exaggerated vascular and renal pathology in endothelin-B receptor-deficient rats with deoxycorticosterone acetate-salt hypertension. Circulation 2000; 102: 2765-2773.

23. Hayashi T, Mori T, Sohmiya K, Okada Y, Inamoto S, Okuda N, et al. Efficacy of edaravone, a free radical scavenger, on left ventricular function and structure in diabetes mellitus. $J$ Cardiovasc Pharmacol 2003; 41: $923-929$.

24. Xu ZG, Lanting L, Vaziri ND, Li Z, Sepassi L, Rodriguez-Iturbe B, et al. Upregulation of angiotensin II type 1 receptor, inflammatory mediators, and enzymes of arachidonate metabolism in obese Zucker rat kidney: Reversal by angiotensin II type 1 receptor blockade. Circulation 2005; 111: $1962-1969$.

25. Ryan S, Taylor CT, McNicholas WT. Selective activation of inflammatory pathways by intermittent hypoxia in obstructive sleep apnea syndrome. Circulation 2005; 112: 2660-2667.

26. Yamashita K, Discher DJ, Hu J, Bishopric NH, Webster KA. Molecular regulation of the endothelin-1 gene by hypoxia: Contributions of hypoxia-inducible factor-1, activator protein-1, GATA-2, AND p300/CBP. J Biol Chem 2001; 276: 12645-12653.

27. Sato H, Sato M, Kanai H, Uchiyama T, Iso T, Ohyama Y, et al. Mitochondrial reactive oxygen species and c-Src play a critical role in hypoxic response in vascular smooth muscle cells. Cardiovasc Res 2005; 67: 714-722.

28. Schäfer M, Schäfer C, Ewald N, Piper HM, Noll Th. Role of redox signaling in the autonomous proliferative response of endothelial cells to hypoxia. Circ Res 2003; 92: 1010-1015.

29. Kawano H, Toda G, Nakamizo R, Koide Y, Seto S, Yano K. Valsartan decreases type I collagen synthesis in patients with hypertrophic cardiomyopathy. Circ J 2005; 69: 1244-1248.

30. Agata J, Nagahara D, Kinoshita S, Takagawa Y, Moniwa N, Yoshida $\mathrm{D}$, et al. Angiotensin II receptor blocker prevents increased arterial stiffness in patients with essential hypertension. Circ J 2004; 68: $1194-1198$.

31. Nakamura Y, Yoshiyama M, Omura T, Yoshida K, Izumi Y, Takeuchi K, et al. Beneficial effects of combination of ACE inhibitor and angiotensin II type 1 receptor blocker on cardiac remodeling in rat myocardial infarction. Cardiovasc Res 2003; 57: 48-54. 